\title{
A Functional and Operational Comparison between Signalized and Unsignalized Roundabouts
}

\author{
Oday Rashed ${ }^{\mathrm{a}}$, Rana Imam $^{\mathrm{b}}$ \\ ${ }^{a}$ Graduate Student, Department of Civil Engineering, The University of Jordan, Amman, Jordan. \\ ${ }^{b}$ Associate Professor, Department of Civil Engineering, The University of Jordan, Amman, Jordan.
}

ORCID: 0000-0003-4576-6053 (Rana Imam)

\begin{abstract}
This research aims to evaluate the operational performance of unsignalized roundabouts, and compare them with signalized roundabouts. Signal optimization was performed then the microscopic simulation software, PTV Vissim, was used to simulate alternatives using the collected traffic data. For the purpose of this research, five roundabouts around the city of Amman were selected, all being urban roundabouts, experiencing a high level of congestion and affecting the operational performance of surrounding intersections.

Traffic signals are not always the most favored solution for solving roundabout problems, because there are criteria to meet and procedures to be followed to justify the merits of adopting a signalized roundabout design. The process of converting an unsignalized roundabout into a signalized one requires defining a signal installation approach and includes many other technical and operational specifications. In general signalized roundabouts are favorable when one or more dominant movement take up an unequal share of the available capacity, or when a small but persistent volume of traffic passes in front of a giveaway line where a very high volume of traffic is trying to egress.
\end{abstract}

At the end of the study, the performance of both signalized and unsignalized roundabouts were evaluated based on multiple measures of effectiveness (MOE), such as: average delay, maximum queue length, and the level of service (LOS). It was also concluded that the average delay of the signalized roundabouts was improved by (9\% to $35 \%)$ and the LOS improved by two levels. However, no improvement was evident in maximum queue length, since any improvement in maximum queue length in one approach causes deterioration in the others.

Keywords: Signalized roundabout, unsignalized roundabouts, microscopic simulation, PTV Vissim.

\section{INTRODUCTION}

Priority controlled roundabouts offer an excellent means for sharing the available capacity by separating and managing conflicting movements within a single intersection. However, these 'give-way' roundabouts break down when one or more dominant movements take up an unequal share of the available capacity, or when a small but persistent volume of traffic passes in front of a giveway line where a very high volume of traffic is trying to egress. By placing signals on a 'failed' priority roundabout, it is possible to more equably share the available capacity between all the approach arms. In so doing, immediately a better practical reserve capacity is achieved for the intersection as a whole.

Innovative traffic signal system design allows traffic to flow through the roundabout with minimal stoppage. The vehicle stream entering the roundabout follows an anticlockwise sequence, whereby the signal start up and cut off losses are minimized. Despite some undesirable driver behaviors, the roundabout has operated safely and effectively as an intersection replacement (Chard, 2006). The ease to switch the traffic over to new motorway alignments also demonstrates the versatility of the roundabout for temporary traffic management.

Signalized roundabouts present an excellent traffic engineering solution for balancing the operational performance of all approaches while improving traffic safety for all the road users. The initial concept of a give-way controlled roundabout was considered unacceptable in the early stage of the design process (Chard, 2006). With unbalanced flows one leg would dominate over the others and there would not be adequate gaps in the circulating flow. Some form of signalization was considered necessary because the traffic volumes were too high and unbalanced to allow for adequate gap.

The quality of the road networks does not solely depend on the features of the roads, but also on the quality of the links between them (Ritveld, 1995). When traveling from a point to another on a road network, transferring from one class of road to another, efficient interchanges and intersections provide continuity which evaluates the quality of a network from the perspective of travelers. Signalized roundabouts are an increasingly popular form of junction control. The first experiments with adding signals to selected arms of existing roundabouts (at peak hours only) were carried out in the late 1950s but it was not until the early 1990s that the use of signals at roundabouts really began to grow (Ridding, 2009). Since then, analysis and control techniques have developed rapidly along with increased requirements for the consideration of pedestrians and cyclists. As a consequence, the design of signalized roundabouts has become very complex and is now a specialized field in its own right. Experience in the design of both roundabouts and complex traffic signal junctions is not enough to guarantee an optimum design for a signalized 
roundabout. Layouts and control strategies are less than optimum and in many cases there are aspects which do not comply with national regulations.

This paper will address this important topic by investigating five implementations of signalized roundabouts. To start with a literature review of previous studies on signalized roundabouts is discussed. Following on, the five roundabouts of the study area will be identified and described. Then, an evaluation of the performance after signalization for each roundabout will be conducted. Afterwards, a comparison between the signalized and unsignalized scenarios will be made. Finally, the conclusions and recommendations of this study will be presented.

\section{LITERATURE REVIEW}

Akcelik et al. (2006) studied the effect of traffic delay, degree of saturation, pollution and fuel consumption on roundabouts with and without metering signal. The analyses were carried out using the SIDRA software package to achieve a reasonable comparison between each case at the end of the study. There are many examples of roundabouts with unbalanced flow patterns in Australia, where part-time roundabout metering signals are used to create gaps in the circulating stream in order to solve the problem of excessive queuing and delays at approaches affected by highly directional flows. The use of metering signals is a cost effective measure to avoid the need for fully-signalized intersection treatment. A case study was later presented comparing a roundabout with and without metering signals in terms of operating cost, fuel consumption, pollutant emissions, delay, and degree of saturation. Similarly, Dryland and Chong (2007) conducted a study about a roundabout in New Zealand, with high traffic volumes and unequal traffic flow distribution through the roundabout. Under the existing situation, placing signals at specific points through the roundabout would minimize stoppage, thus positively affect drivers and pedestrian safety. The internal queue length was minimized using a very short cycle length (less than 1 minute). The roundabout design was also unique in its geometry, road markings, signs, and other design aspects. Furthermore, Natalizio (2005) established a comparison between a conventional roundabout that was mainly controlled by a giveaway sign and a signalized roundabout that was controlled by traffic signals. Multiple criteria were used to measure the efficiency of each choice and explaining the benefits of using traffic signal on queues, delays, safety, capacity, and pedestrian volumes. The study summarized some of the results in useful figures that can be used to decide on which approach should be controlled by traffic signal based on traffic volume conditions for each approach. The figures also described the traffic volume at which traffic signals and giveaway signs fail to control the roundabout.

Ridding (2009) provided a new guidance note on design recommendations for signalized roundabouts. He suggests treating each case individually, yet bearing in mind the common general design considerations related to geometric design, pedestrian facilities, forecasted traffic demand, signing and markings, and other issues related to roundabouts. Likewise, Chard et al. (2015) provided several examples from
New Zealand of signalized roundabout design, including: Welcome Bay Roundabout, Maungatapu Roundabout, and Brookfield Roundabout. The study discussed multiple design considerations that should be applied when designing signal controlled roundabouts. Design considerations were mainly related to road markings, safety, cycle time, and available design options. The importance of this study lies in the fact that it provides a detailed methodology on how to design signalized roundabouts that successfully serve road users.

Finally, Vogt el al. (2014) developed a screening tool which aids engineers in efficiently evaluating when a roundabout is warranted. The tool is designed to be used in retrofit situations, as it provides a clear step-by-step set of considerations when evaluating a potential roundabout location. The tool guides engineers in analyzing context sensitive and qualitative factors that could be easily overlooked during initial analyses. Major evaluation objectives include safety, operations, traffic calming, spatial requirements, environmental factors, and aesthetics. The data required to evaluate these objectives includes: collision history, cost of collisions, road geometry, speed limits, mode interaction/split, traffic volumes, and turning movements. Surrounding land use is an additional consideration both with respect to acquisition cost as well as potential constructability issues. Vogt et al. [8] consolidated the information obtained from both the consultation with multiple jurisdictions as well as a review of relevant literature to provide a comprehensive source on roundabouts for a mid-sized urban area. The consolidated information combined with the screening tool serve to provide a foundation for the City of Winnipeg to evaluate roundabouts in future intersection retrofit situations and support future policy consideration.

\section{STUDY AREA}

To achieve the purpose of this study, five highly congested roundabouts along a major arterial, Zahran Street, were selected as the study area. Zahran Street contains eight roundabouts, named sequentially from first to eighth circle, and connects multiple major business districts in Amman with high levels of congestion. The five roundabouts chosen are the $4^{\text {th }}$, $5^{\text {th }}, 6^{\text {th }}, 7^{\text {th }}$, and $8^{\text {th }}$ circles (shown in Figure 1 ) to compare the proposed signalized roundabouts with their priority controlled counterpart roundabouts. Due to the unbalanced traffic volume that seeks to pass the roundabout, a queue is formed at one or more roundabout legs, while the other intersecting roads end up having a relatively low average delay time and a short queue of vehicles.

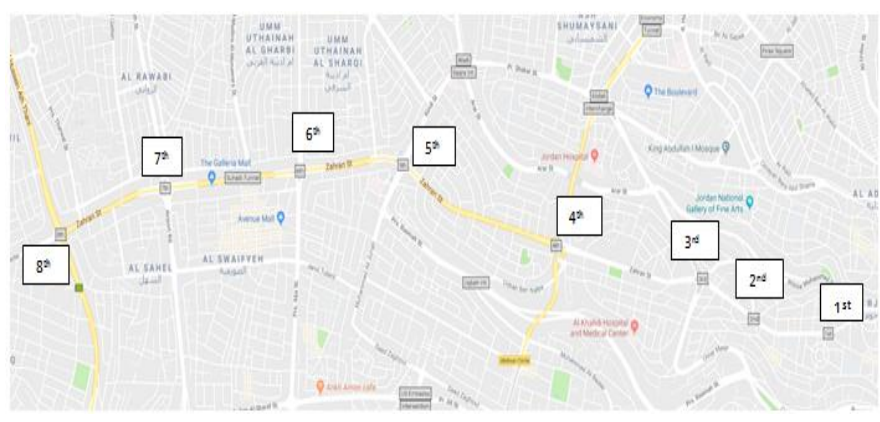

Figure 1: Study Area-Zahran Street (Google Maps 2018). 


\section{METHODOLOGY}

Traffic data is the primary source of data for this study. The origin-destination (O-D) data was provided by the Greatest Amman Municipality (GAM), and traffic counts from 2018 were adjusted with a $3 \%$ growth rate to 2020 according to the Amman Master Plan (2012). For comparison purposes, the traffic volumes were applied to simulate the operational performance for both scenarios. First, it was applied on the models considering the priority controlled (unsignalized) roundabout option. Second, it was applied on the models considering the signalized roundabout option.

\section{RESULTS}

The performance of both signalized and unsignalized roundabouts were evaluated based on multiple measure of effectiveness (MOE) such as average delay, maximum queue length, and level of service (LOS). To build the traffic simulation models, the microscopic simulation platform package, PTV Vissim, was used to analyze the existing traffic conditions and simulate the signalized scenarios.

Three cases of roundabout signalization were considered in this study:

1- Partially signalized roundabout concept, where not all the approaches are controlled by traffic signals, was applied on the $8^{\text {th }}$ Circle.

2- Fully signalized roundabout concept, where all the approaches are controlled by traffic signals, was applied on the $4^{\text {th }}$ and $7^{\text {th }}$ Circles.

3- Partially signalized roundabout concept, where Left Turn slip lanes were provided through the central island to allow for smoother operation, was applied on the $5^{\text {th }}$ and $6^{\text {th }}$ Circles.

\subsubsection{Fourth Circle}

Figure 2 illustrates the Fourth Circle of Zahran Street. Initial analysis revealed that the give-way controlled roundabout was considered unacceptable due to unbalanced flows; where one leg dominates over the others leaving no adequate gaps in the circulating flow. Some form of signalization is necessary as the traffic volumes are too high and unbalanced to allow for adequate gap creation and selection. As more site specific constraints were identified during the process, the need for a fully signalized roundabout became apparent. For the unsignalized Fourth Circle scenario, it operates at LOS F, with an average delay of 120 seconds. This poor performance is a result of being a political and diplomatic hub. The Prime Ministry, Algerian, Canadian, Egyptian, French, Kuwaiti, Omani, Spanish, and Tunisian embassies are all located in this leafy area. These destinations attract and produce a large number of trips resulting in high traffic volumes at certain roundabout entries while the other entries are under-utilized. However, in the case of using s left turn signalized roundabout, the LOS of the Fourth Circle remained at level F, but the average delay drops to $110 \mathrm{sec}$. A slight improvement could be achieved, as shown in Table 1.

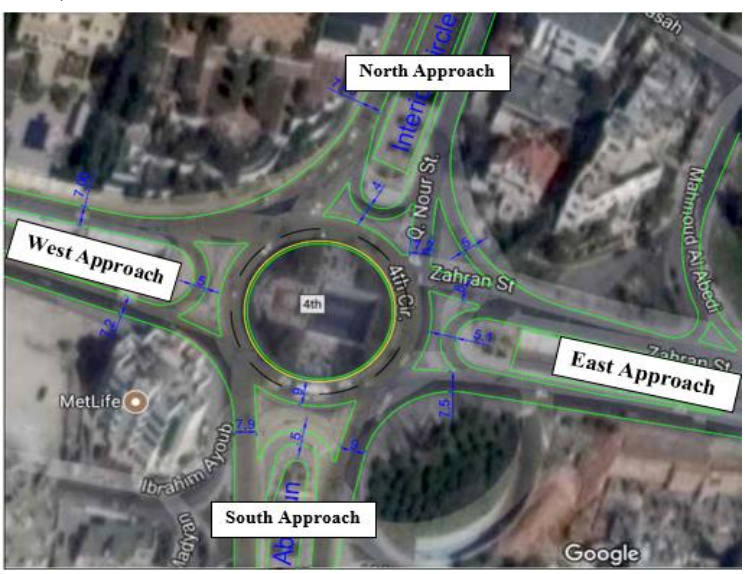

Figure 2: Fourth Circle

Table 1: Fourth Circle Results*

\begin{tabular}{|c|c|c|c|c|c|c|c|c|c|c|}
\hline & & & \multicolumn{8}{|c|}{ To } \\
\hline & & & \multicolumn{2}{|c|}{ South Approach } & \multicolumn{2}{|c|}{ East Approach } & \multicolumn{2}{|c|}{ North Approach } & \multicolumn{2}{|c|}{ West Approach } \\
\hline \multirow{16}{*}{ 总 } & \multirow{4}{*}{$\begin{array}{c}\text { West } \\
\text { Approach }\end{array}$} & LOS & B & $\mathrm{F}$ & $\mathrm{F}$ & $\mathrm{D}$ & B & $\mathrm{D}$ & A & $\mathrm{D}$ \\
\hline & & Average Delay (s) & 12.03 & 504.73 & 59.62 & 504.73 & 11.17 & 504.73 & 4.7 & 504.73 \\
\hline & & Maximum Queue(m) & 112.04 & 83.96 & 112.04 & 38.15 & 112.04 & 49.8 & 112.04 & 50.03 \\
\hline & & Volume (veh/h) & \multicolumn{2}{|c|}{104} & \multicolumn{2}{|c|}{118} & \multicolumn{2}{|c|}{1612} & \multicolumn{2}{|c|}{43} \\
\hline & \multirow{4}{*}{$\begin{array}{c}\text { East } \\
\text { Approach }\end{array}$} & LOS & $\mathrm{F}$ & $\mathrm{E}$ & $\mathrm{F}$ & $\mathrm{C}$ & $\mathrm{F}$ & B & $\mathrm{F}$ & $\mathrm{E}$ \\
\hline & & Average Delay(s) & 192.92 & 40.29 & 179.53 & 40.29 & 117.16 & 40.29 & 102.17 & 40.29 \\
\hline & & Maximum Queue(m) & 68.4 & 73.23 & 68.4 & 21.71 & 282.13 & 17.16 & 68.4 & 78.53 \\
\hline & & Volume (veh/h) & \multicolumn{2}{|c|}{175} & \multicolumn{2}{|c|}{54} & \multicolumn{2}{|c|}{160} & \multicolumn{2}{|c|}{138} \\
\hline & \multirow{4}{*}{$\begin{array}{c}\text { North } \\
\text { Approach }\end{array}$} & LOS & $\mathrm{F}$ & A & $\mathrm{F}$ & A & A & A & $\mathrm{F}$ & A \\
\hline & & Average Delay(s) & 141.04 & 3.3 & 140.92 & 2.71 & 0 & 7.77 & 140.57 & 4.44 \\
\hline & & Maximum Queue(m) & 392 & 159.08 & 392 & 159.08 & 392 & 159.08 & 392 & 159.08 \\
\hline & & Volume (veh/h) & \multicolumn{2}{|c|}{324} & \multicolumn{2}{|c|}{48} & \multicolumn{2}{|c|}{3} & \multicolumn{2}{|c|}{2326} \\
\hline & \multirow{4}{*}{$\begin{array}{c}\text { South } \\
\text { Approach }\end{array}$} & LOS & A & A & A & B & B & $\mathrm{C}$ & $\mathrm{D}$ & $\mathrm{D}$ \\
\hline & & Average Delay (s) & 94.57 & 2.03 & 94.57 & 16.9 & 94.57 & 25.82 & 94.57 & 38.8 \\
\hline & & Maximum Queue (m) & 1.44 & 101.3 & 4.28 & 101.3 & 13.29 & 101.3 & 26.83 & 101.3 \\
\hline & & Volume (veh/h) & \multicolumn{2}{|c|}{108} & \multicolumn{2}{|c|}{500} & \multicolumn{2}{|c|}{1123} & \multicolumn{2}{|c|}{277} \\
\hline
\end{tabular}

*Left-hand columns describe the signalized roundabout; right-hand columns describe the signalized roundabout. 


\subsubsection{Fifth Circle}

Figure 3 illustrates the Fifth Circle of Zahran Street. If a signalized roundabout with left turn lanes is proposed for this roundabout, these slip lanes would allow for a smoother operation during the AM and PM peak periods by removing heavy traffic movements from the circulating signalized traffic stream. These could also be exclusive for buses or certain classes of vehicles. Also the signalization of roundabout could be full or partial depending on the traffic volumes and other factors. The unsignalized Fifth Circle operates at LOS F with an average delay of 81.75 seconds. It serves a busy hotel district where 6 major hotels (The Four Seasons Hotel, Sheraton Amman Hotel, The St Regis Hotel, The Fairmont, The Ritz Carlton, and The Bristol Hotel) are within an area of $1 \mathrm{~km}^{2}$. On the other hand, for the partially signalized roundabout design, the signalized Fifth Circle would have a LOS D, with an average delay of 54.30 seconds. This is a significant improvement in the overall performance of the roundabout, as shown in Table 2.

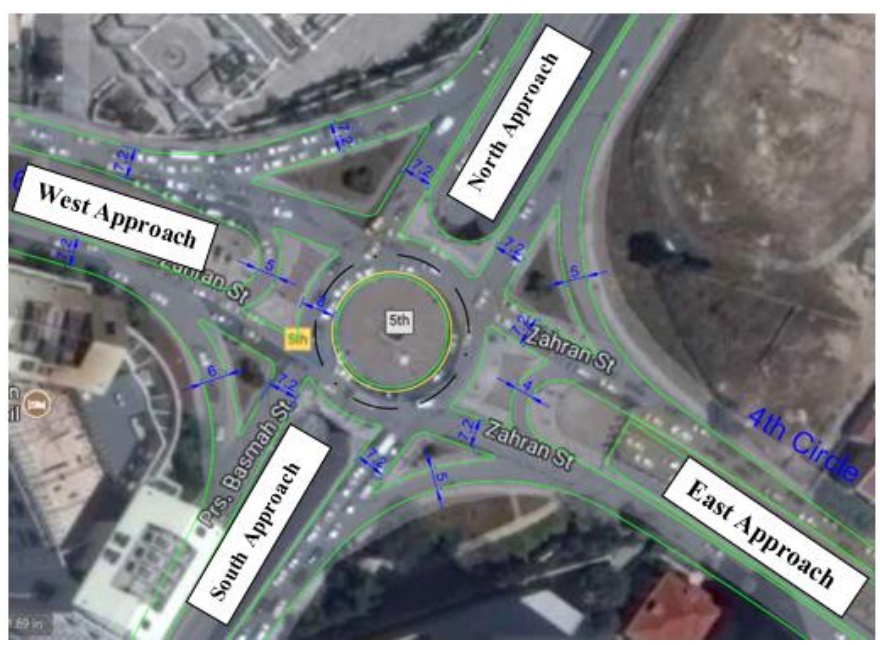

Figure 3: Fifth Circle

Table 2: Fifth Circle Results*

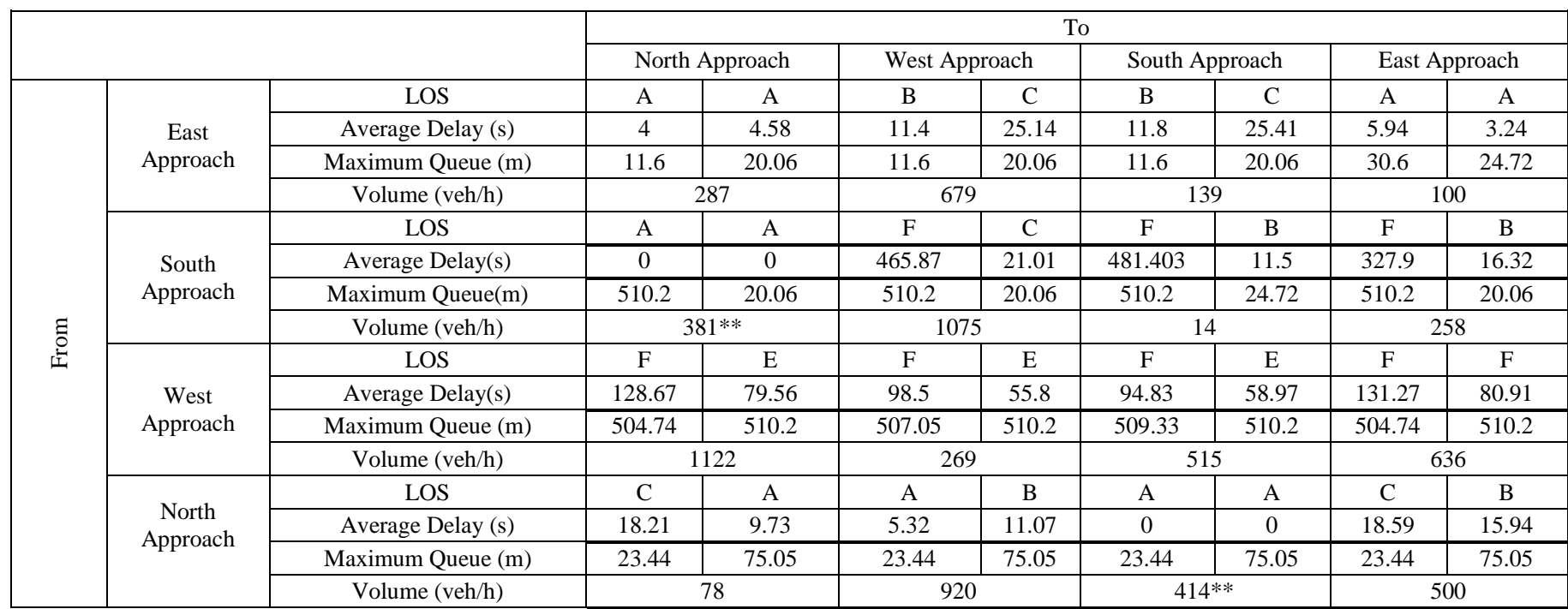

*Left-hand columns describe the signalized roundabout; right-hand columns describe the signalized roundabout.

** Almost all vehicles are crossing the roundabouts through bridges or tunnel.

\subsubsection{Sixth Circle}

Figure 4 illustrates the Sixth Circle of Zahran Street. The current operation of the $6^{\text {th }}$ circle has resulted in serious congestion problems leading to delays and traffic accidents. The unsignalized Sixth Circle operates at a LOS F, with an average delay of 88.22 seconds. The area is a commercial district with nearby high-rise towers. In case of adopting a signalized roundabout with left turn lanes, the LOS of the Sixth Circle improves to LOS E, with an average delay of 62.35 seconds. Therefore, a significant improvement could be achieved, as shown in Table 3.

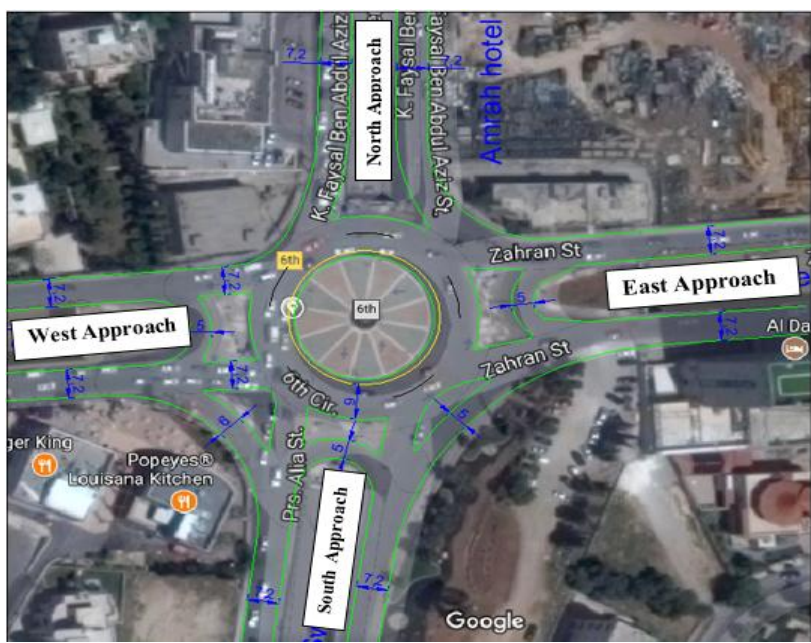

Figure 4: Sixth Circle 
International Journal of Engineering Research and Technology. ISSN 0974-3154, Volume 13, Number 6 (2020), pp. 1448-1454

(C) International Research Publication House. https://dx.doi.org/10.37624/IJERT/13.6.2020.1448-1454

Table 3: Sixth Circle Results*

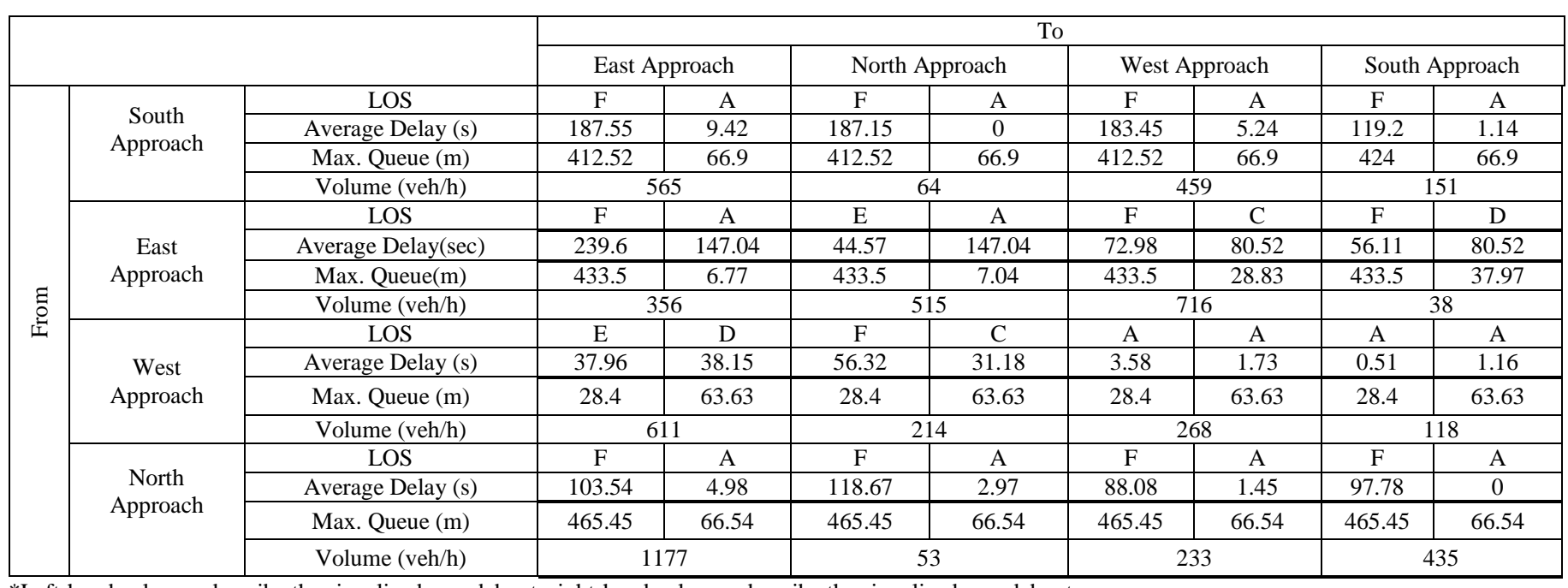

*Left-hand columns describe the signalized roundabout; right-hand columns describe the signalized roundabout.

\subsubsection{Seventh Circle}

Figure 5 illustrates the Seventh Circle of Zahran Street. The unsignalized Seventh Circle operates at LOS F, with an average delay of 122.2 seconds. It is located in an area of commercial and business activities, schools, shopping malls, and restaurants. Nevertheless, in case of applying a signalized roundabout design with left lanes, the LOS remains $F$ with an average delay of 115.35 seconds. This represents a slight improvement in the overall performance of the roundabout, as shown in Table 4.

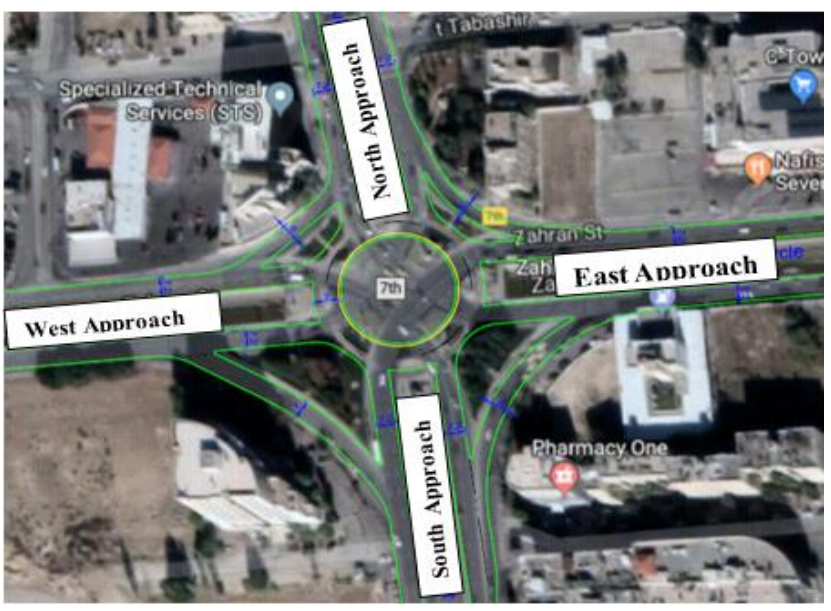

Figure 5: Seventh Circle

Table 4: Seventh Circle Results*

\begin{tabular}{|c|c|c|c|c|c|c|c|c|c|c|}
\hline & & & \multicolumn{8}{|c|}{ To } \\
\hline & & & \multicolumn{2}{|c|}{ East Approach } & \multicolumn{2}{|c|}{ North Approach } & \multicolumn{2}{|c|}{ West Approach } & \multicolumn{2}{|c|}{ South Approach } \\
\hline \multirow{16}{*}{ ฐี } & \multirow{4}{*}{$\begin{array}{c}\text { South } \\
\text { Approach }\end{array}$} & LOS & $\mathrm{F}$ & $\mathrm{F}$ & $\mathrm{A}$ & A & $\mathrm{F}$ & $\mathrm{F}$ & $\mathrm{F}$ & $\mathrm{E}$ \\
\hline & & Average Delay (s) & 157.1 & 89.01 & 0 & 0 & 105.52 & 101.81 & 89.73 & 63.47 \\
\hline & & Max. Queue (m) & 510.2 & 510.2 & 510.2 & 510.2 & 510.2 & 510.2 & 510.2 & 510.2 \\
\hline & & Volume (veh/h) & \multicolumn{2}{|c|}{2691} & \multicolumn{2}{|c|}{$682 * *$} & \multicolumn{2}{|c|}{517} & \multicolumn{2}{|c|}{281} \\
\hline & & LOS & $\mathrm{F}$ & $\mathrm{F}$ & $\mathrm{F}$ & $\mathrm{F}$ & $\mathrm{A}$ & $\mathrm{A}$ & $\mathrm{F}$ & $\mathrm{F}$ \\
\hline & & Average Delay (s) & 120.07 & 117.44 & 113.32 & 115.35 & 0 & 0 & 127.01 & 125.71 \\
\hline & Approach & Max. Queue (m) & 152.09 & 100.17 & 152.09 & 100.17 & 152.09 & 100.17 & 152.09 & 100.17 \\
\hline & & Volume (veh/h) & \multicolumn{2}{|c|}{662} & \multicolumn{2}{|c|}{262} & \multicolumn{2}{|c|}{$322 * *$} & \multicolumn{2}{|c|}{1426} \\
\hline & \multirow{4}{*}{$\begin{array}{c}\text { West } \\
\text { Approach }\end{array}$} & LOS & $\mathrm{A}$ & A & $\mathrm{F}$ & $\mathrm{F}$ & $\mathrm{F}$ & $\mathrm{F}$ & $\mathrm{F}$ & $\mathrm{F}$ \\
\hline & & Average Delay (s) & 0 & 0 & 119.49 & 111.24 & 117.02 & 115.34 & 112.46 & 114.05 \\
\hline & & Max. Queue (m) & 105.76 & 119.39 & 105.76 & 119.39 & 105.76 & 119.39 & 105.76 & 119.39 \\
\hline & & Volume (veh/h) & \multicolumn{2}{|c|}{$614 * *$} & \multicolumn{2}{|c|}{380} & \multicolumn{2}{|c|}{335} & \multicolumn{2}{|c|}{179} \\
\hline & \multirow{4}{*}{$\begin{array}{c}\text { North } \\
\text { Approach }\end{array}$} & LOS & $\mathrm{B}$ & $\mathrm{C}$ & $\mathrm{A}$ & A & A & $\mathrm{A}$ & $\mathrm{A}$ & A \\
\hline & & Average Delay (s) & 12.44 & 22.18 & 3.65 & 4.63 & 3.1 & 2.62 & 0 & 0 \\
\hline & & Max. Queue (m) & 77.8 & 66.37 & 77.8 & 66.37 & 77.8 & 66.37 & 77.8 & 66.37 \\
\hline & & Volume (veh/h) & \multicolumn{2}{|c|}{622} & \multicolumn{2}{|c|}{533} & \multicolumn{2}{|c|}{158} & \multicolumn{2}{|c|}{$304 * *$} \\
\hline
\end{tabular}

*Left-hand columns describe the signalized roundabout; right-hand columns describe the signalized roundabout.

** Almost all vehicles are crossing the roundabouts through bridges or tunnel 
International Journal of Engineering Research and Technology. ISSN 0974-3154, Volume 13, Number 6 (2020), pp. 1448-1454

(C) International Research Publication House. https://dx.doi.org/10.37624/IJERT/13.6.2020.1448-1454

\subsubsection{Eighth Circle}

Figure 6 illustrates the Eighth Circle of Zahran Street. Not all the entries need to be signal controlled. Indeed, leaving one or more entry under priority control often provides better progression for all the traffic through the roundabout. If not all the arms are signalized, one or more arms are left as giveway. Full signal control requires more storage space for queuing within the roundabout, having only three signal controlled arms is more ideal. In such cases, no new entering traffic into the roundabout will be stopped at the first stop line within the roundabout. Not stopping the traffic at the first stop line after entering the roundabout is now a recommended safety requirement. Perfect progression is achieved if only three arms are signalized. It is noted that a good progression means that traffic newly released into the signaled roundabout travels all or a significant way through the roundabout without being stopped at an internal stop line. The following points decide which approach should be left as giveway:

1- The entry flow being low (below $850 \mathrm{pcu} / \mathrm{h}$ in both peak periods);

2- There is sufficient stacking room for gap takers to store at the next stop line within the roundabout; and

3- There is a closely associated signal controlled roundabout node to provide inter-stage gaps.
The priority controlled Eighth Circle operates at LOS F, with an average delay of 127.10 seconds. The area is a medical district encompassing four main hospitals. One the other hand, in case of adopting a signalized roundabout with left turns, the overall performance of this roundabout would not improve; since the LOS remains at level $\mathrm{F}$ with an average delay of 121.30 seconds. This indicates that no improvement was achieved, as shown in Table 5.

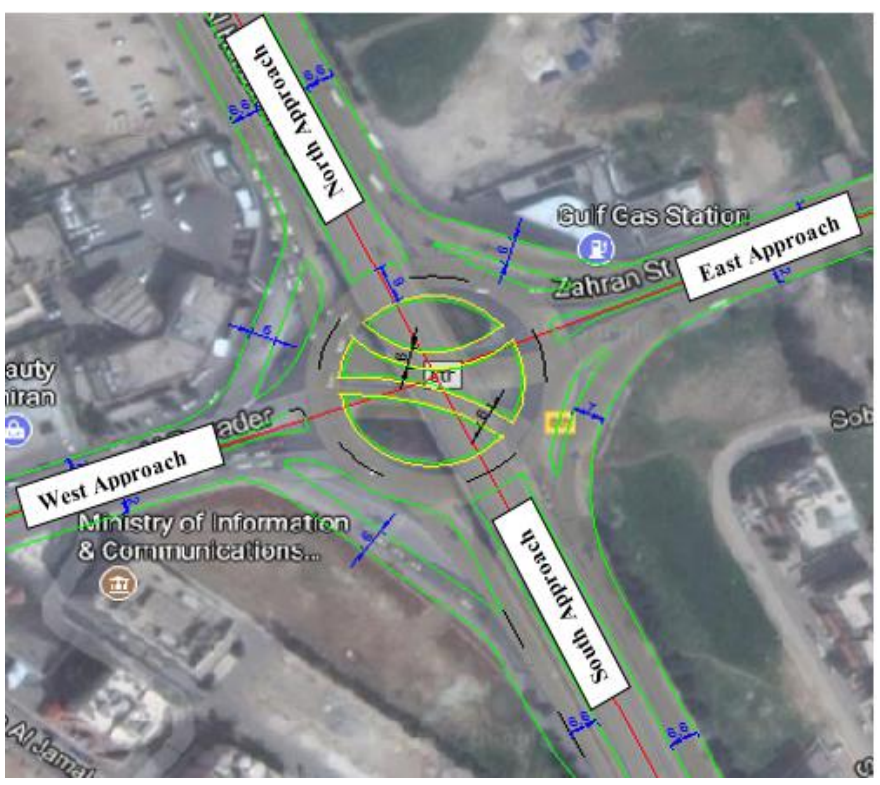

Figure 6: Eighth Circle

Table 5: Eighth Circle Results*

\begin{tabular}{|c|c|c|c|c|c|c|c|c|c|c|}
\hline & & & \multicolumn{8}{|c|}{ To } \\
\hline & & & \multicolumn{2}{|c|}{ South Approach } & \multicolumn{2}{|c|}{ West Approach } & \multicolumn{2}{|c|}{ North Approach } & \multicolumn{2}{|c|}{ East Approach } \\
\hline \multirow{16}{*}{$\underset{0}{\Xi}$} & \multirow{4}{*}{$\begin{array}{c}\text { West } \\
\text { Approach }\end{array}$} & LOS & $\mathrm{F}$ & $\mathrm{F}$ & $\mathrm{F}$ & $\mathrm{F}$ & $\mathrm{F}$ & $\mathrm{F}$ & $\mathrm{F}$ & $\mathrm{F}$ \\
\hline & & Average Delay (s) & 70.45 & 48.23 & 71.55 & 50.45 & 72.45 & 51.35 & 70.63 & 49.43 \\
\hline & & Max. Queue (m) & 510.13 & 342.54 & 510.13 & 342.54 & 510.13 & 342.54 & 510.13 & 342.54 \\
\hline & & Volume (veh/h) & 309 & 1033 & 1356 & 312 & 309 & 1033 & 1356 & 312 \\
\hline & \multirow{4}{*}{$\begin{array}{c}\text { South } \\
\text { Approach }\end{array}$} & LOS & B & $\mathrm{C}$ & A & B & A & $\mathrm{C}$ & B & $\mathrm{C}$ \\
\hline & & Average Delay (s) & 13.32 & 24.52 & 5.37 & 16.48 & 9.5 & 20.67 & 10.68 & 22.48 \\
\hline & & Max. Queue (m) & 24.55 & 41.72 & 24.55 & 41.72 & 24.55 & 41.72 & 24.55 & 41.72 \\
\hline & & Volume (veh/h) & \multicolumn{2}{|c|}{2010} & \multicolumn{2}{|c|}{122} & \multicolumn{2}{|c|}{100} & \multicolumn{2}{|c|}{473} \\
\hline & \multirow{4}{*}{$\begin{array}{c}\text { North } \\
\text { Approach }\end{array}$} & LOS & $\mathrm{F}$ & $\mathrm{F}$ & $\mathrm{F}$ & $\mathrm{F}$ & $\mathrm{F}$ & $\mathrm{F}$ & $\mathrm{F}$ & $\mathrm{E}$ \\
\hline & & Average Delay (s) & 518.63 & 305.73 & 279.65 & 80.43 & 287.55 & 89.46 & 243.22 & 63.22 \\
\hline & & Max. Queue (m) & 510.21 & 492.55 & 510.21 & 492.55 & 510.21 & 492.55 & 510.21 & 492.55 \\
\hline & & Volume (veh/h) & \multicolumn{2}{|c|}{420} & \multicolumn{2}{|c|}{207} & \multicolumn{2}{|c|}{243} & \multicolumn{2}{|c|}{54} \\
\hline & \multirow{4}{*}{$\begin{array}{c}\text { East } \\
\text { Approach }\end{array}$} & LOS & $\mathrm{F}$ & $\mathrm{F}$ & $\mathrm{F}$ & $\mathrm{F}$ & $\mathrm{F}$ & F & $\mathrm{F}$ & $\mathrm{F}$ \\
\hline & & Average Delay (s) & 346.42 & 157.42 & 405.53 & 204.53 & 394.27 & 186.27 & 306.14 & 124.14 \\
\hline & & Max. Queue (m) & 510.21 & 337.16 & 510.21 & 337.16 & 510.21 & 337.16 & 510.21 & 337.16 \\
\hline & & Volume (veh/h) & \multicolumn{2}{|c|}{1043} & \multicolumn{2}{|c|}{48} & \multicolumn{2}{|c|}{236} & \multicolumn{2}{|c|}{176} \\
\hline
\end{tabular}

*Left-hand columns describe the signalized roundabout; right-hand columns describe the signalized roundabout. 


\section{CONCLUSIONS AND RECOMMENDATIONS}

Signalization enhances the operational efficiency of roundabouts. It is particularly effective when unacceptable vehicle delay occur due to high traffic volumes from one; causing unacceptable queues at downstream entries. No evidence was identified to suggest that a signalization would degrade roundabout traffic operations. When traffic signals are installed that stop both entry and exit traffic at the same time, allowing pedestrians to cross from both directions, queues back up into the circulating roadway and disrupt traffic operations.

In this study, the performance of both signalized and unsignalized roundabouts were evaluated based on multiple MOE, such as: average delay, maximum queue length, and the level of service (LOS). It was also concluded that the average delay of the signalized roundabouts was improved by ( $9 \%$ to $35 \%$ ) and the LOS improved by two levels. However, no improvement was evident in maximum queue length, since any improvement in maximum queue length in one approach causes deterioration in the others.

Implementation of different options of signalization at roundabouts could lead to improvements in the operational performance, according to the simulation results. However, the simulation software excludes the driver's expectation, which affects the traffic flow and may cause accidents and safety hazards. Future research could investigate the safety implications of signalized roundabouts; both positive and negative. Also, the development of empirical relations to predict the performance of a signalized roundabout based on its geometric characteristics is recommended.

\section{REFERENCES}

[1] B.H. Al-Omari, H.R. Al-Masaeid, and Y.S. AlShawabkah, Development of a delay model for roundabouts in Jordan, ASCE Journal of Transportation Engineering, Vol. 130 (1):76-80, 2004.

[2] H.R. Al-Masaeid, M.Z. Fedda, Capacity of roundabouts in Jordan, Transportation Research Record: Journal of the Transportation Research Board, Vol. 1572 (1): 76$85,1998$.

[3] R. Akcelik, Analysis of Roundabout Metering Signals, $25^{\text {th }}$ AITPM National Conference, Melbourne, Australia, 2006.

[4] R.E. Allsop, Selection of offsets to minimize delay to traffic in a network controlled by fixed-time signals, Transportation Science, Vol. 2 (1): 1-13, (1968).

[5] R.E. Allsop, Delay-minimizing settings for fixed-time traffic signals at a single road junction, IMA Journal of Applied Mathematics, Vol. 8(2): 164-185, 1971.

[6] R. E. Allsop, Sensitivity of delay at a fixed time traffic signal to small errors in the observations used for calculating signal settings, Traffic Flow and Transportation, (Elsevier, London, pp. 253-268, 1972).

[7] B. Chard, Signalled Roundabouts and their Design $A$ 1Day Workshop, 2006.
[8] B. Chard, R. Thomson, and A. Bargh, Signal controlled roundabout methodology and its introduction to NZ at Welcome Bay, Maungatapu and Brookfield roundabouts in Tauranga North Island, (2015).

[9] D. R. Dryland, E.L. Chong, Design and implementation of a signalised roundabout: SH20 Hillsborough Ring Road. Road and Transport Research, Vol. 17(2):60-71, 2008.

[10] FHWA Federal Highway Administration (2004). Signalized Intersections: Informational Guide (FHWAHRT-04-091), pp. 219-276.

[11] Federal Highway Administration (2008). Traffic Signal Timing Manual. U.S. Department of Transportation. Publication Number: FHWA-HOP-08-024.

[12] J. Headrick, and W. Uddin, Traffic flow microsimulation for performance evaluation of roundabouts and stopcontrolled intersections at highway overpass, Advances in Transportation Studies Journal, Vol. 34: 7-18, 2014.

[13] E. Natalizio, Roundabouts with metering signals, Institute of Transportation Engineers Annual meeting, Melbourne, Australia, August 2005.

[14] T. Obaidat, F.A. Abu Al-Bandoura, and H. Al-Masaeid, Traffic Safety at Roundabouts in Urban Areas - Case Study in Jordan, The $5^{\text {th }}$ Jordan International Civil Engineering Conference (JICEC), Amman, Jordan, 2012.

[15] C. Ridding, S. Phull, Signal Controlled Roundabouts- $A$ New Guidance Paper. In European Transport Conference, 2009.

[16] M. Vogt, K. Poff, S. Suderman, and J. Montufar, Development of a Screening Tool for Roundabout Feasibility in Winnipeg, 2014 Conference of the Transportation Association of Canada Montreal, Quebec, Canada, 2014. 